\title{
Dental Neglect in Children: A Comprehensive Review of the Literature
}

\author{
Maria Kiatipi ${ }^{1}$, Sotiria Davidopoulou ${ }^{2}$, Konstantinos Arapostathis $^{3}$, Aristidis Arhakis ${ }^{4}$
}

\begin{abstract}
Aim: The purpose of this review is to present the most recent bibliography regarding the etiology, risk factor indicators, types of dental neglect, and the epidemiological studies, showing the relationship between neglect and dental caries indices. Moreover, the review will focus on the role of oral healthcare professionals in evaluating such conditions.

Background: Untreated oral diseases, like dental caries, can lead to a variety of negative impacts on children including pain and infection. However, such complications can be prevented if a child's basic oral health needs are fulfilled. In addition, it is important to be aware that there are significant inequalities in accessing dental care and poverty, and such cases have to be distinguished from neglect. However, when there is adequate access to oral healthcare services and the parent or the guardian persistently fails to ensure appropriate medical care or treatment for his/her child, the possibility of dental neglect has to be seriously considered.

Review results: Dental neglect can be apart of a child's general neglect with short-term complications, such as caries, as well as long-term consequences that extend to adulthood, such as poor growth and impaired quality of life.

Conclusion: Early diagnosis of dental neglect plays an important role in avoiding adverse impacts on children. Signs and risk factors for dental neglect should alert the dental team in order to intervene in time and prevent suspected cases.

Clinical significance: Diagnosis of dental neglect can be difficult. However, identifying dental neglect at an early stage and making a child protection referral may safeguard the child and prevent further harm. For this reason, dentists should be informed about dental neglect and they should know how to deal with these cases. Effective education is necessary to increase knowledge and awareness of all aspects of child neglect.

Keywords: Child neglect, Dental caries, Dental neglect.

The Journal of Contemporary Dental Practice (2021): 10.5005/jp-journals-10024-3019
\end{abstract}

\section{INTRODUCTION}

The United Nations Convention on the Rights of the Child emphasizes that all children should be protected from any kind of maltreatment or neglect and they should be provided with sufficient healthcare services. ${ }^{1}$ The World Health Organization subdivided violence into four types: physical, sexual, psychological, and involving deprivation or neglect. ${ }^{2}$ In England and Wales, children's maltreatment includes physical abuse, psychological abuse, sexual abuse, and general and dental neglect. ${ }^{3}$ Children are more likely to be victims of violence and the dominance of neglect compared to other forms of violence is worth mentioning. ${ }^{4}$ Neglect is the insistent failure to provide appropriate physical and/ or psychological needs with significant impacts on children's health and development. ${ }^{5}$ In accordance with the National Society for the Prevention of Cruelty to Children in the United Kingdom (UK), 1 in 10 young adults appeared to be a victim of severe neglect when he/she was younger. ${ }^{6}$ It is reported that in the UK, $44 \%$ of children were neglected ${ }^{6}$ and in the United States, this number rose up to $78 \%{ }^{7}$ In Australia, according to a study by Radford and coworkers, $5 \%$ of children who are under 11 years old suffered from neglect and $3.7 \%$ have been strictly neglected. ${ }^{6}$

American Academy of Pediatric Dentistry states that dental neglect is the "willful failure of the parent or guardian, despite adequate access to care, to seek and follow through with treatment necessary to ensure a level of oral health essential for adequate function and freedom from pain and infection. ${ }^{8}$ According to the academy's definition of dental neglect, there are some
${ }^{1}$ School of Dentistry, Aristotle University of Thessaloniki, Thessaloniki, Greece

${ }^{2}$ Department of Preventive Dentistry, Periodontology and Implant Biology, School of Dentistry, Aristotle University of Thessaloniki, Thessaloniki, Greece

${ }^{3,4}$ Department of Paediatric Dentistry, School of Dentistry, Aristotle University of Thessaloniki, Thessaloniki, Greece

Corresponding Author: Aristidis Arhakis, Department of Paediatric Dentistry, School of Dentistry, Aristotle University of Thessaloniki, Thessaloniki, Greece, Phone: +30 2310999454, e-mail: arhakis@dent. auth.gr

How to cite this article: Kiatipi M, Davidopoulou S, Arapostathis K, et al. Dental Neglect in Children: A Comprehensive Review of the Literature. J Contemp Dent Pract 2021;22(2):199-204.

Source of support: Nil

Conflict of interest: None

factors for a layperson that suggest dental neglect and should not be overlooked, such as visible severe dental caries, untreated pain, infection, bleeding, or trauma, and a history of unfinished treatments. ${ }^{9,10}$ However, many people can be unaware of the processes and the implications of a dental disease. If the healthcare provider meticulously explains the existence of the disease, its extension, and the appropriate treatment and despite available access to dental health services if the caregiver fails to obtain therapy, there is a case of dental neglect. ${ }^{10,11}$ 
As there is not such a comprehensive review in the literature, the aim of this article is to present the epidemiology of dental neglect, its etiology, features, and consequences on oral health. Additionally, the characteristics and the awareness of parents of neglected children and the dentist's role in the identification, prevention, and maintenance of high standards of hygiene will also be discussed.

\section{Types of Dental Neglect}

The most common type of dental neglect is untreated carious lesions. ${ }^{10}$ Dental caries, otherwise known as tooth decay, are formed through a complex interaction over time between acidproducing bacteria of dental microbial plaque ${ }^{12}$ and fermentable carbohydrates, mainly sucrose. ${ }^{13,14}$ White spot lesions are the first sign of decayed teeth and if the cariogenic conditions continue cavities will appear. The upper primary incisor teeth are the most prone for decay followed by primary first molars, primary second molars, and canines. The primary lower incisors are usually free of decay due to the mechanical removal of plaque by tongue movements and the presence of abundant saliva. ${ }^{15}$ Early childhood caries (ECC) also known as "nursing bottle caries" and "baby bottle tooth decay" is one of the main characteristics of neglected children. According to the American Academy of Pediatric Dentistry, ECC refers to one or more dental caries (with or without cavities), extractions because of carious lesions, or fillings in any deciduous teeth in children who are younger than 6 years old. ${ }^{16}$

Another type of dental neglect is untreated dental traumas. About $10 \%$ of children aged from 18 months to 18 years may suffer from tooth traumas. ${ }^{17}$ Most cases of tooth injuries due to physical abuse or falls appear in children who are 1 to 3 years old with consequences either in hard dental tissue, dental pulp, or periodontal structures. The upper incisors are more likely to be affected. It is worth mentioning that severe fractures may lead to root canal therapy. Moreover, there may be consequences to the succeeding permanent teeth and in some cases, the injured primary teeth may need extraction. As a result, the dentist's intervention must be immediate in order to avoid direct or future complications. $^{17,18}$

Malocclusion is one of the most common oral pathologies after dental caries and periodontal disease. Incorrect oral habits and abnormalities regarding the number, shape, or developmental position of teeth are some factors that can lead to malocclusion. Negligence in providing appropriate treatment for malocclusion at the right age can result in adverse incidences, such as dental caries, periodontitis, ${ }^{19}$ or temporomandibular joint dysfunction. ${ }^{20}$ Furthermore, individuals may have low self-esteem, ${ }^{21}$ as their facial appearance is disfigured. ${ }^{22}$

Dental neglect can be separated into active, passive, or selfneglect. This classification depends on the reasons for dental neglect. Active neglect concerns the cases when parents or guardians fail to provide necessary treatment on purpose. On the contrary, parents or guardians may be uninformed about the oral health problem and the appropriate oral health care needed and unaware of the available dental services or they even suffer from disabilities or financial difficulties. In such cases, the neglect is considered passive. Moreover, self-neglect is the neglect due to children's inability to express or meet their own needs due to physical, mental, or developmental disabilities. ${ }^{23}$ Dental neglect can also be subdivided into dental-prevention neglect and dental-treatment neglect. Dental-prevention neglect is the lack of preventive measures while dental-treatment neglect is the failure of providing appropriate dental treatment. Both of them may lead to untreated dental caries, traumatic dental injuries, dental pain, or inflammation. ${ }^{24}$

\section{Epidemiology}

Dental caries is the single most common chronic disease of childhood. ${ }^{25}$ By 5 years of age, approximately $60 \%$ of children have experienced caries in their primary dentition. ${ }^{26}$ A study in Portugal showed that $88 \%$ of 6 -year-old children had carious lesions on primary teeth. ${ }^{27}$ In the USA, $78 \%$ of children have suffered from caries by age $17 .^{28}$ In addition, $90 \%$ of all caries in school-age children appear in pits and fissures. ${ }^{8}$

Research in Pacoti, Brazil, shows a correlation between dental caries indices and neglect in 5-year-old children. Moreover, $60 \%$ of parents seem to be low educated..$^{29}$ One Canadian study found that children who suffered from maltreatment had $50 \%$ more decayed teeth compared to the control group. ${ }^{30}$ Another study in Italy describes the relationship between ECC and child neglect. Sixtythree children were examined and $61.9 \%$ of them were presented with ECC, especially in families with low socioeconomic status. ${ }^{31}$ Another study in Chennai examined 6,000 teenagers aged from 15 to 18 to explore the connection between dental neglect and dental caries and oral health in adolescents. It demonstrated that social and demographic factors are strongly associated with dental neglect. ${ }^{32}$ In some countries, such as the Czech Republic, ${ }^{29}$ Hong Kong, ${ }^{33}$ Philippines, ${ }^{34}$ and Australia, ${ }^{35}$ where primary oral health care and national programs of oral health estimate are not widely accessible, ${ }^{36}$ high caries indices in children are reported. In Sweden, a study regarding 0 - to 6-year-old children that experienced general anesthesia (GA) at a specialist pediatric dentistry clinic from 2006 to 2011, demonstrated that those children suffered more often from dental neglect. $^{37}$

\section{Etiology}

It would be useful to understand the factors that lead to dentally neglectful behaviors and attitudes. It is proved that sociodemographic variables, like age, gender, or socioeconomic class, are associated with dental neglect. ${ }^{38-45}$ Dental neglect can exist at any age (childhood, adolescence, or old ages). However, it is found that children and elders are more likely to suffer from neglectful oral health ${ }^{45}$ while older adolescents have greater levels of dental neglect than younger ones. ${ }^{43,44}$ Several studies have been conducted regarding the occurrence of dental neglect in adolescence. ${ }^{41-45}$ During adolescence due to the eruption of permanent dentition, increased numbers of tooth surfaces may be affected by carious lesions and there is also an increase in early periodontal disease occurrence. In addition, adolescents are more independent from their parents as they start establishing their own oral care habits. Thus, their increasing autonomy may influence their dental attendance. ${ }^{42}$ Elders may suffer from diminished physical and cognitive capabilities that may lead to avoidance of dental care services and poor oral health. ${ }^{46}$

Moreover, it is observed that dental neglect is more common among males than females. ${ }^{36,41,45}$ In addition, low levels of education, ${ }^{39,40,45}$ unemployment, ${ }^{40,45}$ financial difficulties, ${ }^{45}$ and low socioeconomic profile ${ }^{39,41}$ are risk indicators for dental neglect and dental diseases.

Furthermore, it is important that disabled individuals are most prone to either negligence by family members, home care attendants, or institutional healthcare workers or even self-negligence. ${ }^{47}$ Additionally, preschool children and disabled children are more likely to suffer from dental neglect due to 
their lack of independence as well as looked-after children and refugees. $^{24}$

Parents' oral habits play a pivotal role in evaluating their children's oral health. ${ }^{33,48}$ It is proved that parents who had a bad dental experience or are afraid of dentists are more likely to neglect their children's oral health necessities. ${ }^{49}$ According to Goh et al., dental anxiety has a strong correlation with dental neglect. ${ }^{50}$ Additionally, parents who do not care about their oral health and fail to complete treatment plans appear to be more uninterested in their children's dental needs, such as restorative and periodontal treatments. ${ }^{51}$ These parents usually miss appointments repeatedly, often need emergency pain relief, and have poorly performed home oral hygiene and no interest in hygiene education. ${ }^{23,29}$ Moreover, parents are responsible for their children's oral health routine up to the age of 7, so they have to be involved in their dental care. ${ }^{29}$

\section{Consequences of Dental Neglect}

ECC has a noticeable influence on both children and the community. ${ }^{52}$ Dental neglect may affect children's both general health and quality of life. ${ }^{53-58}$ Pain, swelling, inflammation, frequent intake of antibiotics, malnutrition, delays in language development, and an overall impact on playing, learning, and socializing can occur in ECC children. Moreover, increased absence from preschool or school, as well as a reduction of self-esteem, have been observed. Furthermore, an increased need for orthodontic treatment in permanent dentition due to space loss or rotation or misplacement of adjacent teeth ${ }^{29}$ has been recorded..$^{52,57,59,60}$ In addition, in rare severe cases, dental caries in primary teeth can even affect the enamel of succeeding permanent teeth. ${ }^{61}$ Dental management of toddlers with ECC may even be performed under GA. ${ }^{29}$ Taking everything into consideration, ECC is a complex problem that requires special treatment and may interfere with a child's normal growth and development. ${ }^{62}$

\section{Diagnosis of Dental Neglect}

It is important to notice that although dental neglect is common among children, it appears to be extremely difficult to diagnose it. ${ }^{63-65}$ Dental neglect is associated with ethnic, race, socioeconomic, cultural, religious, and educational backgrounds. ${ }^{63,66-68}$ Medical providers have to identify the reasons for untreated dental caries and they have to separate neglect from cases of unawareness or limited access to dental care. ${ }^{69}$

Many factors should be examined like assessment of dental disease, parental awareness, access to dental care, and autonomy of the child. ${ }^{70}$ It is possible that dental decay may be considered by parents as a natural condition of primary teeth which cannot be avoided. ${ }^{29,71}$ Indicators, such as repeatedly missing dental checkups, emergency appointments to get relief from pain on a regular basis, and the necessity of GA for dental care or extractions more than once ${ }^{62,72}$ should be considered in the early identification of dental neglect in children.

Screening questions for children when assessing for dental neglect should include the following: $:^{73}$

- Do you have any problem eating certain foods, like hard, cold, hot, or chewy foods?

- When do you brush your teeth?

- Does anyone help you brush your teeth?

- Do you ever get teased or bullied at school?

- What do they tease you about?

- Have you ever hurt any of your teeth?
Screening questions for parents when assessing for dental neglect should include the following: ${ }^{73}$

- Does anyone in your family have a history of dental problems?

- When was the last time anyone in your family went to the dentist?

- Has your child ever been to a dentist?

- What have you noticed about your child's teeth?

- Do you brush your child's teeth?

- Does your child ever have a bottle or sippy cup in bed?

- Have you ever noticed bleeding from anywhere in your child's mouth?

In 1996, scales were developed for measuring dental indifference ${ }^{74}$ and dental neglect. ${ }^{38}$ Nuttall composed an eight-item scale in order to measure what he defined as "dental indifference." It examined respondents' daily oral health routine, their perspective of dental care, their attitude toward dentist's appointment in the previous 5 years, and their behavior in case of filling loss in a back tooth, painless gum bleeding, and a pretty painful back tooth. ${ }^{40}$ Meanwhile, Thomson et al. suggested a seven-item scale based on the information about behavior and attitude toward oral health. Initially, it was designed for children and parents had to rate their children's dental care performance. Higher scores were related to higher levels of dental neglect in the previous 2 years. ${ }^{38}$ Later, it was modified for adults and it proved the association between dental neglect and poor dental status. ${ }^{41}$ Dental neglect scale was proven to be an easy and useful tool for health services, unaffected by the observation process, to understand variations in dental health and establish health promotion strategies. ${ }^{40-43}$

\section{Discussion and Clinical Significance}

The dental team should be aware of the warning signs of dental neglect as they can help with the identification of a broader neglect in children. ${ }^{75}$ As a result, untreated dental caries could be a hint of a general neglect. ${ }^{62,76}$

In accordance with the National Institute of Health and Care Excellence, the dental team should be suspicious of dental neglect when they detect poor oral health repeatedly and when parents fail to ensure necessary treatments, despite the possible access to dental care. ${ }^{77}$ Powell and Appleton highlighted the difference between "did not attend" and "was not brought." Therefore, public health nurses should pay more attention to the reasons for missing scheduled checkups. ${ }^{78}$ Bradbury-Jones et al. found that public health nurses seldom connect untreated dental caries and child neglect. ${ }^{23}$ In Croatia, $26.27 \%$ of dentists have observed cases of children's maltreatment or neglect and only $5.1 \%$ of them reported it. ${ }^{79}$ In the UK, $81 \%$ of dentists treated neglected children on a regular basis and only $21.4 \%$ of them communicated their concerns with other agencies. ${ }^{80}$ A research, which took place in Scotland in March 2010, showed that the main factor affecting the decision of $74 \%$ of general dental practitioners was the fact that they were not sure of the diagnosis. ${ }^{81}$ In other studies, $50 \%$ of dentists were capable of recognizing indicators of children's maltreatment and neglect but less than $25 \%$ of them knew how to handle this situation. ${ }^{68}$ All healthcare professionals' duty should be to ensure the welfare of children ${ }^{63}$ and they are mandated by law to report any suspicion of child neglect in all appropriate jurisdictions. ${ }^{82}$ However, it is found that lack of proper training or clear guidelines, the uncertainty of the diagnosis, fear of the impact on their practice, fear of parents' aggressive reaction, or even court procedure are some significant factors that prevent the healthcare professionals from reporting neglect. ${ }^{62,80,83}$ 
Consequently, dentists have to be trained properly even during undergraduate dental education to be able to identify dental neglect risk factors. ${ }^{84}$ Since 2015 in the UK, there are mandatory classes of dental neglect's confrontation at undergraduate education. ${ }^{85}$ According to Burgette et al., there is confusion about when there is a child neglect and what the consequences of failing to report child neglect are. Thus, dentists should get informed about the protocols and the current state law regarding reporting child dental neglect. ${ }^{86}$

Dental neglect intervention includes three stages depending on the level of concerns: preventive dental team management, preventive multiagency management, and child protection referral. ${ }^{87}$ The main purpose of the intervention is not to accuse the family or the guardian but to ensure appropriate treatment for children who are at risk of neglect. ${ }^{88}$

Prevention of dental caries is very important. In order to ensure early diagnosis and prevention, the child should see a dentist on his first birthday. ${ }^{89}$ Initially, parents can clean their children's teeth and gums with a damp cloth and when the child is 1 year old, a soft toothbrush can be used. Children should brush their teeth every morning and every night with a fluoride-rich toothpaste in order to have adequate oral hygiene. ${ }^{29}$ The amount of fluoride in a toothpaste depends on the age of children and its "rice size" (0.1 mg fluoride) for children who are younger than 3 years old and "pea size" ( 0.25 mg fluoride) for children who are 3 to 6 years old. Children who are younger than 6 years and are at risk of ECC can be provided with professionally applied fluoride treatments with $5 \%$ sodium fluoride varnish ( $22500 \mathrm{ppm} F$ ). In addition, parents should avoid putting their infants or older children down for a nap with a bottle of milk or juice, and children should follow a proper diet with less snacks and drinks with sugar. By 12 months, children might have developed their eating habits which increase the risk of carious lesions, so it is important to adopt early a proper way of dental care. ${ }^{90}$

Dentists have to inform parents about the techniques and the benefits of proper dental care to improve parents' knowledge toward daily oral health practices as well as correct feeding habits. ${ }^{36}$ In addition, dental treatment planning should be realistic in order to avoid missing appointments and in case of dental anxiety appropriate anxiety management techniques should be used. ${ }^{62}$

Other health-related professionals, such as trained public health nurses, can also discuss with the family about proper dental care $\mathrm{e}^{23,91}$ as they spend time with preschool-aged children and as a result, they can establish formal communication pathways. ${ }^{23}$

Health professionals, like dental hygienists and dental assistants, can also contribute in the recognition and prevention of dental neglect; ${ }^{92}$ they usually are the first to see and spend more time with the patients. As a result, they are able to create a trusting relationship with them, facilitating communication and furthermore, they can obtain more information about patient's characteristics and family background..$^{93}$

Links with other agencies, such as child's health visitor, school nurse, doctor, or social worker if they have one, are important both in terms of being able to provide better support to the family, but also for monitoring the risk factors. ${ }^{62}$

However, if the child is thought to be suffering a significant harm or in case of evident neglect, a child protection referral is recommended. In accordance with legal requirements, accurate mention of warning signs is necessary to prove how they can relate to harm or potential harm of the child and furthermore, a routinely high standard of keeping clinical record can be very useful in these cases. ${ }^{62}$

\section{Conclusion}

Dental neglect is a form of child maltreatment and, if suspected, should be reported to the appropriate child protective agencies. However, dental neglect can be unidentified and as a result, child neglect is underreported. It is possible that dentists do not notice the link between dental caries and child neglect. Moreover, dental neglect is not usually an isolated issue that can lead on its own to child protection referral. Dental professionals have to be aware of the indicators of dental neglect in order to be able to intervene early rather than only when a crisis occurs. The early classification of high-risk groups can improve general oral health and furthermore the quality of life of the patients.

Thus, the dental team is encouraged to be knowledgeable about dental neglect's indices and their significance as well as the serious consequences of neglectful dental care and their importance of reporting. A dentist with formal training can ensure appropriate diagnosis and treatment so emphasis should be placed on this topic as part of undergraduate and postgraduate dental education. Most children do not appear referenced with a history of neglect, so it is up to the dentist to have appropriate sensitivity and training to identify, record, and report these cases.

In addition, interprofessional working is also necessary in the context of early help provisions and multiagency communication should always be considered.

However, when the situation is too complex or deteriorating despite best efforts and there are concerns about possible severe harm from neglect, a child protection referral is vital.

Taking everything into consideration, the prevention of both dental and child neglect requires awareness not only among dentists and other healthcare professionals but also among parents and the general public.

\section{ACKNOWLedgments}

Ethics Approval and Consent to Participate: The manuscript does not report on or involve any animals, humans, human data, human tissue, or plants, hence ethical approval and consent is "not applicable."

Consent for Publication: The manuscript does not contain any individual person's data; hence this section is "not applicable."

Availability of Data and Materials: We do not wish to share the data as the master chart for all the included studies and a detailed list of referred article has already been included.

Authors' contributions: All authors sufficiently contributed in designing, acquiring data, and drafting the article.

\section{References}

1. United Nation General Assembly: Convention on the right of the child; 2012. Available from: http://www.ohchr.org/en/professionalinterest/ pages/crc.aspx.

2. Krug EG, Mercy JA, Dahlberg LL, et al. The world report on violence and health. Lancet 2002;360(9339):1083-1088. DOI: 10.1016/S01406736(02)11133-0.

3. Department of Health. The Children Act 1989. London: Her Majesty's Stationary Office; 1989. Available from: https://www.legislation.gov. uk/ukpga/1989/41/contents.

4. Iossi Silva MA, Carvalho Ferriani MDG. Domestic violence: from the visible to the invisible. Rev Lat Am Enfermagem 2007;15(2):275-281. DOI: 10.1590/s0104-11692007000200013. 
5. Government HM. Healthy lives, healthy people. London: TSO; 2011. Available from: https://www.gov.uk/government/publications/ healthy-lives-healthy-people-our-strategy-for-public-health-inengland.

6. Radford L, Corral S, Bradley C, et al. Child abuse and neglect in the UK today. National Society for the Prevention of Cruelty to Children (NSPCC); 2011. Available from: http://clok.uclan.ac.uk/6022/.

7. United States Children's Bureau. Child maltreatment; 2011. Available from: https://www.acf.hhs.gov/archive/cb/resource/childmaltreatment-2011.

8. Fisher-Owens SA, Lukefahr JL, Tate AR, et al. Oral and dental aspects of child abuse and neglect. Pediatrics 2017;140(2):e20171487. DOI: 10.1542/peds.2017-1487.

9. Sanger G, Bross D. Clinical management of child abuse and neglect: a guide for dental professionals. In: Legal aspects of child abuse. Chicago: Quintessence Pub Co; 1984. p. 109-123.

10. Schwartz S, Woolridge E, Stege D. Oral manifestations and legal aspects of child abuse. J Am Dent Assoc 1977;95(3):586-591. DOl: 10.14219/jada.archive.1977.0120.

11. Clarke A. The choice to refuse or withhold medical treatment: the emerging technological and medical-ethical consensus. Creighton Law Rev 1980;13(spring):795.

12. Loesche WJ. Role of Streptococcus mutans in human dental decay. Microbiol Rev 1986;50(4):353-380.

13. Douglass JM, Li Y, Tinanoff N. Association of mutans streptococci between caregivers and their children. Pediatr Dent 2008;30(5): 375-387.

14. van Loveren C, Buijs JF, ten Cate JM. Similarity of bacteriocin activity profiles of mutans streptococci within the family when the children acquire the strains after the age of 5. Caries Res 2000;34(6):481-485. DOI: 10.1159/000016627.

15. Raphael S. Bottle caries and dental neglect. NSW Public Health Bull 1999;10(4):31-32. DOI: 10.1071/nb99013.

16. American Academy of Pediatric Dentistry. Policy on early childhood caries (ECC): classifications, consequences, and preventive strategies. The reference manual of pediatric dentistry. Chicago, IL: American Academy of Pediatric Dentistry; 2020. p. 79-81.

17. Tinanoff N. Dental trauma. In: Kliegman RM, Stanton B, St Geme JW, et al., editors. Nelson's textbook of pediatrics. Philadelphia: Elsevier; 2011. p. 1258-1259.

18. Josell SD, Abrams RG. Managing common dental problems and emergencies. Pediatr Clin North Am 1991;38(5):1325-1342. DOI: 10.1016/s0031-3955(16)38200-1.

19. Machado AW, MacGinnis M, Damis L, et al. Spontaneous improvement of gingival recession after correction of tooth positioning. Am J Orthod Dentofacial Orthop 2014;145(6):828-835. DOI: 10.1016/j. ajodo.2013.05.012.

20. Fushima K, Inui M, Sato S. Dental asymmetry in temporomandibular disorders. J Oral Rehabil 1999;26(9):752-756. DOI: 10.1046/j.13652842.1999.00447.x.

21. Badran SA. The effect of malocclusion and self-perceived aesthetics on the self-esteem of a sample of Jordanian adolescents. Eur J Orthod 2010;32(6):638-644. DOI: 10.1093/ejo/cjq014.

22. Kiekens RM, Maltha JC, van't Hof MA, et al. Objective measures as indicators for facial esthetics in white adolescents. Angle Orthod 2006;76(4):551-556. DOI: 10.1043/0003-3219(2006)076[0551:OMAIF F]2.0.CO;2.

23. Bradbury-Jones C, Innes N, Evans D, et al. Dental neglect as a marker of broader neglect: a qualitative investigation of public health nurses' assessments of oral health in preschool children. BMC Public Health 2013 Apr 19;13:370. DOI: 10.1186/1471-2458-13-370.

24. Sarri G, Evans P, Stansfeld S, et al. A school-based epidemiological study of dental neglect among adolescents in a deprived area of the UK. Br Dent J 2012;213(10):E17. DOI: 10.1038/sj.bdj.2012.1042.

25. U.S. Department of Health and Human Services. Oral health in America: a report of the surgeon general. Rockville, MD.: U.S. Department of Health and Human Services, National Institute of Dental and Craniofacial Research, National Institutes of Health; 2000.
$\mathrm{NIH}$ publication 00-4713. Available from: https://www.nidcr.nih.gov/ sites/default/files/2017-10/hck1ocv.\%40www.surgeon.fullrpt.pdf.

26. Dye BA, Tan S, Smith V, et al. Trends in oral health status: United States, 1988-1994 and 1999-2004. Vital Health Stat 11 2007;(248):1-92.

27. Von Amann GP, Cádima CF. Estudo Nacional de Prevalência das Doenças Orais. Lisboa: Direcção-Geral da Saúde; 2008.

28. Carmona RH. National call to action to promote oral health. J Am Coll Dent 2005;72(4):8-10.

29. Lourenço CB, Saintrain MV, Vieira AP. Child, neglect and oral health. BMC Pediatr 2013;13:188. DOI: 10.1186/1471-2431-13-188.

30. Valencia-Rojas N, Lawrence HP, Goodman D. Prevalence of early childhood caries in a population of children with history of maltreatment. J Public Health Dent 2008;68(2):94-101. DOI: 10.1111/j.1752-7325.2007.00077.x.

31. Scorca A, Santoro V, De Donno A, et al. Early childhood caries (ECC) and neglect in child care: analysis of an Italian sample. Clin Ter 2013;164(5):e365-e371. DOI: 10.7417/CT.2013.1614.

32. Gurunathan D, Shanmugaavel AK. Dental neglect among children in Chennai. J Indian Soc Pedod Prev Dent 2016;34(4):364-369. DOI: 10.4103/0970-4388.191420.

33. Chu CH, Ho PL, Lo EC. Oral health status and behaviours of preschool children in Hong Kong. BMC Public Health 2012;12(1):767. DOI: 10.1186/1471-2458-12-767.

34. Benzian $\mathrm{H}$, Monse $\mathrm{B}$, Heinrich-Weltzien $\mathrm{R}$, et al. Untreated severe dental decay: a neglected determinant of low Body Mass Index in 12-year-old Filipino children. BMC Public Health 2011;11(1):558. DOI: 10.1186/1471-2458-11-558.

35. Arora A, Scott JA, Bhole S, et al. Early childhood feeding practices and dental caries in preschool children: a multi-centre birth cohort study. BMC Public Health 2011;11(1):28. DOI: 10.1186/1471-2458$11-28$.

36. Begzati A, Berisha M, Meqa K. Early childhood caries in preschool children of Kosovo - a serious public health problem. BMC Public Health 2010;10(1):788. DOI: 10.1186/1471-2458-10-788.

37. Kvist $T$, Zedrén-Sunemo J, Graca E, et al. Is treatment under general anaesthesia associated with dental neglect and dental disability among caries active preschool children? Eur Arch Paediatr Dent 2014;15(5):327-332. DOI: 10.1007/s40368-014-0118-z.

38. Thomson WM, Spencer AJ, Gaughwin A. Testing a child dental neglect scale in South Australia. Community Dent Oral Epidemiol 1996;24(5):351-356. DOI: 10.1111/j.1600-0528.1996.tb00875.x.

39. Acharya S, Pentapati KC, Bhat PV. Dental neglect and adverse birth outcomes: a validation and observational study. Int J Dent Hyg 2013;11(2):91-98. DOI: 10.1111/idh.12001.

40. Jamieson LM, Thomson WM. The Dental Neglect and Dental Indifference scales compared. Community Dent Oral Epidemiol 2002;30(3):168-175. DOI: 10.1034/j.1600-0528.2002.300302.x.

41. Thomson WM, Locker D. Dental neglect and dental health among 26-year-olds in the Dunedin Multidisciplinary Health and Development Study. Community Dent Oral Epidemiol 2000;28(6):414-418. DOI: 10.1034/j.1600-0528.2000.028006414.x.

42. Coolidge T, Heima M, Johnson EK, et al. The Dental Neglect Scale in adolescents. BMC Oral Health 2009;9:2. DOI: 10.1186/1472-6831-9-2.

43. Jamieson LM, Thomson M. Dental health, dental neglect, and use of services in an adult Dunedin population sample. N Z Dent J 2002;98(431):4-8.

44. Skaret E, Astrøm AN, Haugejorden O, et al. Assessment of the reliability and validity of the Dental Neglect Scale in Norwegian adults. Community Dent Health 2007;24(4):247-252.

45. McGrath C, Sham AS, Ho DK, et al. The impact of dental neglect on oral health: a population based study in Hong Kong. Int Dent J 2007;57(1):3-8. DOI: 10.1111/j.1875-595x.2007.tb00111.x.

46. Katz RV, Smith BJ, Berkey DB, et al. Defining oral neglect in institutionalized elderly: a consensus definition for the protection of vulnerable elderly people. J Am Dent Assoc 2010;141(4):433-440. DOI: 10.14219/jada.archive.2010.0196.

47. Jenny C. Child abuse and neglect: diagnosis, treatment, and evidence. St. Louis: Saunders/Elsevier; 2011. p. 589-590. 
48. Amin MS, Harrison RL. Understanding parents' oral health behaviors for their young children. Qual Health Res 2009;19(1):116-127. DOI: $10.1177 / 1049732308327243$.

49. Freeman R. The role of the primary care dentist in safeguarding children. In: Taylor J, ThemesslHuber M, editors. Safeguarding children in primary health care. London: Jessica Kingsley; 2005. p. $60-76$.

50. Goh EZ, Beech N, Johnson NR. Dental anxiety in adult patients treated by dental students: a systematic review. J Dent Educ 2020;84(7):805811. DOI: 10.1002/jdd.12173.

51. Pretty IA, Sweet D. Anatomical location of bitemarks and associated findings in 101 cases from the United States. J Forensic Sci 2000;45(4):812-814.

52. Peres MA, Macpherson LMD, Weyant RJ, et al. Oral diseases: a global public health challenge. Lancet 2019;394(10194):249-260. DOI: 10.1016/S0140-6736(19)31146-8.

53. Reisine ST. Dental health and public policy: the social impact of dental disease. Am J Public Health 1985;75(1):27-30. DOI: 10.2105/ ajph.75.1.27.

54. Low W, Tan S, Schwartz S. The effect of severe caries on the quality of life in young children. Pediatr Dent 1999;21(6):325-326.

55. Inglehart MR, Filstrup SL, Wandera A. Oral health and quality of life in children. In: Inglehart MR, Bagramian RA, editors. Oral health-related quality of life. Chicago: Quintessence Publishing Company; 2002. p. 79-88.

56. Filstrup SL, Briskie D, da Fonseca M, et al. Early childhood caries and quality of life: child and parent perspectives. Pediatr Dent 2003;25(5):431-440.

57. Sheiham A. Dental caries affects body weight, growth and quality of life in pre-school children. Br Dent J 2006;201(10):625-626. DOI: 10.1038/sj.bdj.4814259.

58. Malden PE, Thomson WM, Jokovic A, et al. Changes in parent-assessed oral health-related quality of life among young children following dental treatment under general anaesthetic. Community Dent Oral Epidemiol 2008;36(2):108-117. DOI: 10.1111/j.1600-0528.2007.00374.x.

59. Glick M, Williams DM, Kleinman DV, et al. A new definition for oral health developed by the FDI World Dental Federation opens the door to a universal definition of oral health. J Public Health Dent 2017;77(1):3-5. DOI: 10.1111/jphd.12213.

60. Casamassimo PS, Thikkurissy S, Edelstein BL, et al. Beyond the dmft: the human and economic cost of early childhood caries. J Am Dent Assoc 2009;140(6):650-657. DOI: 10.14219/jada.archive.2009.0250.

61. Broadbent JM, Thomson WM, Williams SM. Does caries in primary teeth predict enamel defects in permanent teeth? A longitudinal study. J Dent Res 2005;84(3):260-264. DOI: 10.1177/154405910508400310.

62. Harris JC, Elcock C, Sidebotham PD, et al. Safeguarding children in dentistry: 2. Do paediatric dentists neglect child dental neglect? $\mathrm{Br}$ Dent J 2009;206(9):465-470. DOI: 10.1038/sj.bdj.2009.356.

63. Kiran K. Child abuse and neglect. J Indian Soc Pedod Prev Dent 2011;29(6 Suppl. 2):S79-S82. DOI: 10.4103/0970-4388.90749.

64. Manea S, Favero GA, Stellini E, et al. Dentists' perceptions, attitudes, knowledge, and experience about child abuse and neglect in northeast Italy. J Clin Pediatr Dent 2007;32(1):19-25. DOI: 10.17796/ jcpd.32.1.f920721252jx3614.

65. Jordan A, Welbury RR, Tiljak MK, et al. Croatian dental students' educational experiences and knowledge in regard to child abuse and neglect. J Dent Educ 2012;76(11):1512-1519.

66. Ivanoff CS, Hottel TL. Comprehensive training in suspected child abuse and neglect for dental students: a hybrid curriculum. J Dent Educ 2013;77(6):695-705

67. Rayman S, Dincer E, Almas K. Child abuse: concerns for oral health practitioners. N Y State Dent J 2013;79(4):30-34.

68. Laud A, Gizani S, Maragkou S, et al. Child protection training, experience, and personal views of dentists in the prefecture of Attica, Greece. Int J Paediatr Dent 2013;23(1):64-71. DOI: 10.1111/j.1365263X.2012.01225.x.

69. Souster $\mathrm{G}$, Innes N. Some clarification of trigger signs for dental neglect. Evid Based Dent 2014;15(1):2-3. DOI: 10.1038/sj.ebd.6400996.
70. Harris JC, Balmer RC, Sidebotham PD. British Society of Paediatric Dentistry: a policy document on dental neglect in children. Int J Paediatr Dent 2018;28(5):e14-e21. DOI: 10.1111/j.1365263x.2009.00996.x.

71. Stevens CL. Is dental caries neglect? Br Dent J 2014;217(9):499-500. DOI: 10.1038/sj.bdj.2014.950.

72. Cairns AM, Welbury RR. The role of the dental team in child protection-a review. Scott Med J 2009;54(2):37-40. DOI: 10.1258/ rsmsmj.54.2.37.

73. Berger S, California Society of Pediatric Dentistry. Dental neglect when to report. California Pediatrician 1989(Fall);1:31-32.

74. Nuttall NM. Initial development of a scale to measure dental indifference. Commun Dent Oral Epidemiol 1996;24(2):112-116. DOI: 10.1111/j.1600-0528.1996.tb00825.x.

75. Taylor J, Lauder W, Moy M, et al. Practitioner assessments of 'good enough' parenting: factorial survey. J Clin Nurs 2009;18(8):1180-1189. DOI: 10.1111/j.1365-2702.2008.02661.x.

76. Balmer R, Gibson E, Harris J. Understanding child neglect. Current perspectives in dentistry. Prim Dent Care 2010;17(3):105-109. DOI: 10.1308/135576110791654883.

77. National Collaborating Centre for Women's and Children's Health (2009). When to suspect child maltreatment. London: RCOG Press.

78. Powell J, Appleton J. Children and young people's missed health care appointments: reconceptualising 'did not attend' to 'was not brought'. A review for the evidence for practice. J Res Nurs 2012;17(2):181-192. DOI: 10.1177/1744987112438158.

79. Cukovic-Bagic I, Dumancic J, Kujundzic Tiljak M, et al. Croatian dentists' knowledge, experience, and attitudes in regard to child abuse and neglect. Int J Paediatr Dent 2015;25(6):444-450. DOI: 10.1111/ipd.12151.

80. Bhatia SK, Maguire SA, Chadwick BL, et al. Characteristics of child dental neglect: a systematic review. J Dent 2014;42(3):229-239. DOI: 10.1016/j.jdent.2013.10.010.

81. Harris CM, Welbury R, Cairns AM. The Scottish dental practitioner's role in managing child abuse and neglect. Br Dent J 2013;214(9):E24. DOI: 10.1038/sj.bdj.2013.435.

82. Saini N. Child abuse and neglect in India: time to act. Japan Med Assoc J 2013;56(5):303-309.

83. Seth R. Protection of children from abuse and neglect in India. Japan Med Assoc J 2013;56(5):292-297.

84. Ramazani N. Child dental neglect: a short review. Int J High Risk Behav Addict 2014;3(4):e21861. DOI: 10.5812/ijhrba.21861.

85. General Dental Council. Preparing for practice 2012. Available from: http://www.gdcuk.org/.

86. Burgette JM, Safdari-Sadaloo SM, Van Nostrand E. Child dental neglect laws: Specifications and repercussions for dentists in 51 jurisdictions. J Am Dent Assoc 2020;151(2):98-107.e5. DOI: 10.1016/j. adaj.2019.09.010.

87. Sharma A. Dental neglect leading to foreign body in tooth. J Orofacial Res 2013;3(4):263-265. DOI: 10.5005/jp-journals-10026-1108.

88. Kirankumar SV, Noorani H, Shivprakash PK, et al. Medical professional perception, attitude, knowledge, and experience about child abuse and neglect in Bagalkot district of north Karnataka: a survey report. J Indian Soc Pedod Prev Dent 2011;29(3):193-197. DOI: 10.4103/09704388.85807.

89. Yu SM, Bellamy HA, Kogan MD, et al. Factors that influence receipt of recommended preventive pediatric health and dental care. Pediatrics 2002;110(6):e73. DOI: 10.1542/peds.110.6.e73.

90. American Academy of Pediatric Dentistry, Council on Clinical Affairs. Policy on Early Childhood Caries (ECC): classifications, consequences, and preventive strategies. Pediatr Dent 2018;40(6):60-62.

91. Heads D, Ahn J, Petrosyan V, et al. Dental caries in children: a sign of maltreatment or abuse? Nurs Child Young People 2013;25(6):22-24. DOI: 10.7748/ncyp2013.07.25.6.22.e121.

92. Mouden LD. Child abuse and neglect: the dental assistant's role in prevention. Dent Assist 2000;69(1):30-37.

93. Sperber ND. Bite marks, oral and facial injuries--harbingers of severe child abuse? Pediatrician 1989;16(3-4):207-211. 